\title{
Hyperprofessionalism and the Crisis of Readership in the History of Science
}

\section{Citation}

Shapin, Steven. 2005. Hyperprofessionalism and the crisis of readership in the history of science. Isis 96(2): 238-243

\section{Published Version}

http://dx.doi.org/10.1086/431535

\section{Permanent link}

http://nrs.harvard.edu/urn-3:HUL.InstRepos:3219883

\section{Terms of Use}

This article was downloaded from Harvard University's DASH repository, and is made available under the terms and conditions applicable to Other Posted Material, as set forth at http:// nrs.harvard.edu/urn-3:HUL.InstRepos:dash.current.terms-of-use\#LAA

\section{Share Your Story}

The Harvard community has made this article openly available.

Please share how this access benefits you. Submit a story.

\section{Accessibility}




\title{
Hyperprofessionalism and the Crisis of Readership in the History of Science
}

\author{
By Steven Shapin*
}

\begin{abstract}
There is a crisis of readership for work in our field, as in many other academic disciplines. One of its causes is a pathological form of the professionalism that we so greatly value. "Hyperprofessionalism" is a disease whose symptoms include self-referentiality, self-absorption, and a narrowing of intellectual focus. This essay describes some features and consequences of hyperprofessionalism in the history of science and offers a modest suggestion for a possible cure.
\end{abstract}

$\mathrm{T}$ HERE IS A CRISIS OF READERSHIP in the history of science. It is not a crisis unique to this field, though of course there are aspects of it that take specific forms in our subject. The crisis is one of pertinence: we are not producing work that many people outside our field want to read and even that colleagues in different parts of our own field want to read. This crisis of pertinence may be something more than a failure of abilityour individual capacities to write things that get a readership. It may be what many of us intend, or at least what our institutional apparatus is geared up to produce and in whose results we acquiesce. That is to say, we have collaborated in shrinking our own readership, and we have done so just at the point when the history of science has so much to say to the wider culture and when there is so much evidence of wide cultural interest in science and its past. The circumstance that has delivered us to our present crisis is, under another description, one of our greatest achievements: the history of science has become one of the academic professions. We enjoy the benefits of academic professional standing, so we must also consider some of its handicaps.

Academic professionalism is a very good thing. To be an academic is to master the facts, theories, methods, purposes, canons, and conventions of your discipline. If you do not master these things, your readers may not know how to place your work and you will

* Department of the History of Science, Harvard University, Science Center 371, Cambridge, Massachusetts 02138

Isis, 2005, 96:238-243

(c) 2005 by The History of Science Society. All rights reserved.

$0021-1753 / 2005 / 9602-0005 \$ 10.00$ 
run the risk of not having an academic audience. Interdisciplinarity is also a good thing, just on the condition that it means you become accomplished in more than one discipline and not that you playfully shirk the responsibilities of becoming proficient in any. Disciplines restrict and narrow perception, but they also define problems, procedures, possible solutions, and an audience for our productions. If you cannot become proficient in disciplinary conventions, you may find it hard to make yourself intelligible. As Thomas Kuhn taught us, the effect of disciplinary narrowing is not necessarily conservative. Disciplines provide the structures against which you can push, if you are so minded, and which allow their claims and conclusions to be intelligibly criticized.

But disciplinary professionalism can easily tip over into a pathological form, which may be called hyperprofessionalism. One mark of hyperprofessional disciplines is that they are self-referential. They conflate the professional literature with the things-in-the-world to which that literature purportedly refers; they equate literature citing with learning and the "building of bridges" between subdisciplinary orientations with genuine creativity. They fetishize expository conventions and treat them as self-evident virtues. They shun as heretics those who stray too far off approved disciplinary terrain. They take disciplinary intelligibility to be the same as intellectual intelligibility, and, in general, they tend to find the noses right in front of their faces hard to see. As the saying is, hyperprofessional disciplines don't get out enough. Attracting interest in the common culture, and meeting its concerns partway, is seen as vulgar. Hyperprofessionalism is death by purification. Hyperprofessional practices may be academic, but they are not intellectual. They are nothing to be so very proud of.

Just so there is no mistaking my point, I offer two specific examples of current American self-referential academic practices: much of philosophy and much of sociology. These practices have bounded themselves so effectively, and enforced disciplinary conventions so forcefully, that they have lost a substantial sense of aboutness. "Doing philosophy," as it is currently practiced, is often more about dexterity in manipulating the disciplinary literature than it is about knowledge, mind, or morals. "Doing sociology," similarly, is in large part a display of methodological virtuosity and of knowing familiarity with the discipline's currently fashionable "models." You can tell a self-referential discipline by the fact that no one reads its products who doesn't have to. Disciplinary members have to, or at least they acknowledge a moral responsibility to do so. Beyond those boundaries readership drops off like a cliff face. Professional success is indexed by insularity. And a mark of a hyperprofessional discipline-in-trouble is that graduate students read the stuff that their senior professors only pretend to have read. Graduate students have to; senior professors have to say they have. Self-referentiality is not an aspect of hyperprofessionalism that much afflicts the history of science, while the neighboring protodiscipline called science and technology studies shows only early symptoms of the disease. So self-referentiality is one way in which hyperprofessional practices produce a crisis of readership, but by no means the only way.

Bad writing definitely shrinks readership. Bad writing is a problem in the history of science, as it is in practically every other present-day academic discipline, but I do not think that historians of science write worse than other academics. The field currently has some exceptional stylists, and many of the problems of academic writing that one finds in the history of science are so pervasive that there is little to say on the matter that is particular to the discipline. But the problem to which it is worth drawing attention is the particular species of bad writing that is, so to speak, institutionally intentional. Initiates learn to write 
badly as a badge of professionalism; they resist using the vernacular because it doesn't sound smart enough; they infer from obscurity to profundity. Some things are indeed hard to say in ordinary English, but not nearly so many as academics pretend. Physicists write jargon far more arcane than sociologists', nor is it obvious that their jargon is always more excusable than that of sociologists, but the institutional fact of the matter is that they can get away with it. Physicists, and natural scientists in general, have other things to offer the powers and the culture than the intelligibility of their products. In the humanities and social sciences, unintelligibility is lethal. I once ran a writing seminar for sociology graduate students. I think they enjoyed it, and maybe they even learned something, but when they told me that the seminar was of no use in getting published in the "mainstream" journals of the field, I couldn't disagree. It may be necessary to write badly-in-the-approved-style to get published in the journals, but it is a guarantee that you won't be read outside the journals.

More and more academic monographs and papers are written for the "files"- as aids in the construction of a career-and not to be read. The current U.S. News \& World Report survey of graduate schools remarks on "academic monographs well suited for tenure committees, but ill-suited for bookstores," and quotes the editorial director of Columbia University Press as saying that "in some ways, we're producing widgets no one wants." We are increasingly successful in not being read: twenty years ago, academic monographs would sell about a thousand copies; now the figure is closer to three or four hundred. Princeton University Press is said to be contemplating a future in which library sales of monographs will be fewer than two hundred. Subjects explicitly mentioned as "on the block" in the publishing plans of academic presses include "literary criticism, linguistics, and the history of science." It just won't do to blame diminishing sales solely on restrictions on university library acquisition budgets and the rising costs of journal subscriptions. These considerations are indeed important, but there would be no "crisis in academic publishing" if readers in the next academic discipline, not to mention what used to be called the "educated common reader," saw interest in the books we produce. That's the sort of thing that academic authors have under their control; they can do little about the economics of scholarly publishing.

If the history of science does not suffer from more than usually clunky writing, or from the worst forms of self-referentiality, what are its other entitlements to being called hyperprofessional? Here is a concrete example: it concerns an oral presentation, but the problems arising attach all the more forcefully to written performances. I was recently in the audience for a talk by a historian of science on-and here I will massage the topic to protect the guilty - theories of heredity in eighteenth-century Italy. The historian was well reputed and well established. As is drearily typical these days, there was no attempt at wit, giving pleasure, or wearing learning lightly, though the delivery satisfied currently modest expectations of liveliness. The scholarship — so far as I could tell—was impressive. The fundamental problem with the talk, as with much that appears in the pages of our academic journals, was that the speaker gave me no reason to be interested in the subject. If I cared

\footnotetext{
${ }^{1}$ Justin Ewers, "Publish or Perish," U.S. News \& World Report: America's Best Graduate Schools, 2005 Edition (Washington, D.C.: U.S. News \& World Report, 2004), p. 65 (quotation). See also Andrew Cooper, "Overcoming the Crisis in Academic Publishing," 100-Day Dialogue, Topic 2, 4 Aug. 2000: http://www.honco.net/100day/02/ 2000-0804-cooper.html [accessed 20 Aug. 2004]. The figures are from Monica McCormick of the University of California Press. The Princeton University Press speculation about library sales is in John Sutherland, "Diary," London Review of Books, 22 Jan. 2004, 26(2):31.
} 
about, or could be made to care about, eighteenth-century Italian hereditary theories, then

I was all right; if not, so far as the speaker was concerned, tant pis. Self-referentiality was not the problem here; it was the self-absorption that is another mark of hyperprofessionalism. The work I was being told about came neither framed nor motivated. I was not told why someone who had concerns other than eighteenth-century Italian hereditary thinking should care about this material. While the performance came "contextualized" in something like the currently accredited manner, it was not connected to passages of culture that temporally or thematically neighbored it. I either got to grips with the stuff on the speaker's narrow terms or I sat through the presentation - as we are all trained to do-feigning polite interest, but in fact thinking about what wine to have with my dinner.

I can assure you that I was not alone: academic colloquia these days are sometimes very dishonest occasions. My guess is that at most colloquia more than half of the audience is not "there" - if they are civilly minded, they are desperately trying to arrange their faces to simulate rapt attention; if they are not, they are correcting proofs or reading a newspaper tactically positioned on the floor. (I've even heard of a wireless senior academic who does his e-mail during colloquia, but I can't make myself believe that's really so.) I don't know whose response I most respect. For both sorts - the hypocritically polite and the unconscionably rude - the problem is the same: they haven't been given any substantial inducements to connect what they know and care about with what's on offer. We do owe speakers and writers the courtesy of our attention, but some of them make it so hard for us to connect that a certain wandering of focus is not our fault.

There are many ways of connecting. One is to sacrifice a bit of hard-won special knowledge. That's not something that many historians are keen to do: after all, we've been funded to find things out that no one else has found out, and we're going to take the occasion to put on show just how much we've found out. Every scrap of it. The virtuosity of specialization is causally, if contingently, related to the epidemic of textual gigantism sweeping the academy. Anyone old enough to have composed a paper or book on a typewriter, still more using a goose's quill dipped in ink, will appreciate just how much easier it's become to add stuff: another fact, another literature citation, another qualification. Everything's gotten longer. "Ctrl-C, Ctrl-V" has much to answer for. The strategy of "mine is longer than yours" seems a pretty good way to win prizes, promotion, and competing job offers you can take to your dean, but it's a lousy way of encouraging your work to be read. If you really want to be read, then try conciseness and economy.

There is much current concern with the lack of "big picture" history of science, but I am not convinced that this is a plausible way of accounting for the current crisis of readership. ${ }^{2}$ It is true that many of our research areas have become empirically narrow, and it is remarkable that no one with any real standing in our field has had the interest, the nerve, or the nous to write a book called The History of Science for more than half a century. ${ }^{3}$

${ }^{2}$ John V. Pickstone, Ways of Knowing: A New History of Science, Technology, and Medicine (Manchester: Manchester Univ. Press, 2000). The British Society for the History of Science convened a "Big Picture" meeting in 1991 (see British Journal for the History of Science, 1993, 26[4]), and in 1993 the Fontana History of Science series was launched with another such conference at the Science Museum in London.

${ }^{3}$ I am well aware of a couple of praiseworthy examples that come close, though even here the full obligation to give an account of the "field" is declined: e.g., Richard Olson, Science Deified and Science Defied: The Historical Significance of Science in Western Culture, 2 vols. (Berkeley: Univ. California Press, 1982). James E. McClellan III and Harold Dorn's fine Science and Technology in World History: An Introduction (Baltimore: Johns Hopkins Univ. Press, 1999) is largely structured around the relations between science and technology. Peter Bowler and Iwan Morus have just published a notable go at Modern Science: A Historical Survey (Chicago: 
But there is no reason to equate circumscribed empirical foci with pedantry or the empirically small scale with the interpretatively trivial: the universe may be legible in a grain of sand, sermons can be read in stones of any size, and well-framed case studies are among the discipline's finest products. The problem is not the scale of what we write about but our interest in writing about our subjects and the connections we make as we write about them. When Walter Bagehot said that "the bane of philosophy is pomposity," it was because "people will not see that small things are the miniatures of greater."4

Moreover, certain versions of what has traditionally been meant by the "big picture" deserve to be rejected. Big pictures imply coherence, and, if historians of science still believe in old versions of scientific coherence (the conceptual unity and universality of science, narratives of rational and linear progress, a specifiable and efficacious scientific method), then most of us do so in a much more qualified sense than we once did. Others do not believe in such coherences at all-I am one of them-and therefore ways of composing a big picture demand not just steeling our nerves but a radical rethinking of the identity of our subject matter. There is an important sense in which the absence of bigpicture narratives in the history of science should be celebrated as a positive accomplishment. $^{5}$

What cannot, however, be viewed with complacency is the self-absorption, if not the self-referentiality, that comes with hyperprofessionalism. We owe our audiences a sense of "aboutness" that brings them into our conversations rather than excludes them. If traditional "big pictures" are not the solution to the crisis in readership, nevertheless, a certain connectedness must be. In my own line of work, a maxim of method-not an epistemological evaluation-has been to treat science as a typical form of culture. Whatever can be learned from the detailed, naturalistic study of a particular scientific practice may be applied to our overall understandings of knowledge and the conditions of its making. ${ }^{6}$ Studies of science can therefore engage the interests of anyone concerned with culture, cognition, language, or social or material practice. A study of eighteenth-century Italian theories of heredity, framed and motivated that way, may be as pertinent to such concerns as anything else. Of course, many historians are not that way inclined; nor, despite my own preferences, is there any necessity that they should be. So I have a modest suggestion about how we might break the constraints of self-absorption and remake an audience for the history of science.

Imagine that you are the historian whose special expertise is Italian theories of heredity in the eighteenth century. Then imagine that you are at a dinner party with a selection of your friends, each of whom has special knowledge in some other domain (not necessarily

Univ. Chicago Press, 2005) from the Scientific Revolution to the present. My reference to "half a century" ago points to Stephen F. Mason, A History of the Sciences (New York: Collier, 1962), originally published as Main Currents of Scientific Thought: A History of the Sciences (New York: Schuman, 1953). This book is still in print and is widely used in teaching the history of science.

${ }^{4}$ Walter Bagehot, Physics and Politics; or, Thoughts on the Application of the Principles of "Natural Selection" and "Inheritance" to Political Society (1872; London: Kegan Paul, Trench, Trübner, 1905), p. 91.

${ }^{5}$ See esp. Roger Smith, "The Big Picture: Writing Psychology into the History of the Human Sciences," Journal of the History of the Behavioral Sciences, 1998, 34:1-13. For positive aspects of rejecting the traditional big picture of the Scientific Revolution see, e.g., Roy Porter, "The Scientific Revolution: A Spoke in the Wheel?" in Revolution in History, ed. Porter and Mikuláš Teich (Cambridge: Cambridge Univ. Press, 1986), pp. 290316.

${ }^{6}$ As originally urged by Barry Barnes in Scientific Knowledge and Sociological Theory (London: Routledge \& Kegan Paul, 1974); and Barnes, Interests and the Growth of Knowledge (London: Routledge \& Kegan Paul, 1977). 
to do with history or with science), and each of whom you regard as at least as intelligent as yourself. Your friends then ask you what you're up to (why it's interesting, what its point is). You may think I am describing the conventions of High Table at Oxford or Cambridge, but not quite. While I am making it easier for you by giving you universityeducated imaginary friends, it will be helpful to suppose that some of them are not academics. The constraints are given by the mode of civility pertaining to the situation: you cannot answer them by giving them a stack of offprints, by embarking on a fifty-minute lecture, or by presuming the proprietary knowledge and special sensibilities of your academic discipline. You owe them an answer that is economical and intelligible and that speaks to concerns that they may plausibly be assumed already to have. You would never think of patronizing these friends - remember that they are as blessed with native intelligence as yourself and that they can take on any bit of knowledge and understand any argument, provided that you make these pertinent and concisely intelligible - but remember also that, because one of them is an intellectual property lawyer, another a neurologist, and still another a mechanical engineer, they may not be too sure just when the Enlightenment happened, what form it took in Italy, what "epigenesis" means, or what kinds of circumstances commended theories of the inheritance of acquired characteristics. They may also not appreciate that the current task of the historian of science is to interpret past culture as it actually was, rather than to award points to those who best anticipated the present. The exercise that you have taken on yourself is probably not best described as "popularization": these friends are not your students, and the tone you are well advised to adopt in responding to their questions is not one commonly found in explicitly popularizing and pedagogical works. You may struggle in acquitting the imaginary task I have set for you; and if you do struggle, consider it possible that you lack a fundamental understanding of your own special subject. But if you succeed, my advice would be to write down what you have said and consider framing your next academic exercise in exactly the same terms. You may not want to do so every time-after all, tenure, promotion, and prizes put bread on the table-but think about it if you want your work to be widely read. Who knows? It may start a trend. 